\title{
International Congress on Whiplash Associated Disorders - The Bern Symposium
}

\author{
Harold Merskey DM FRCP \\ Editor-in-Chief, Pain Research \& Management
}

W e take pleasure in this issue in presenting a series of plenary session lectures and some additional contributions from the Bern Symposium, a meeting held in Berne, Switzerland from March 8 to 10, 2001. The symposium was organized by Dr Bogdan Radanov and colleagues from that city where they had themselves undertaken an enormous amount of classical work in the investigation of cervical sprain syndrome. Radanov's work resolved a number of definitive issues in the investigation of whiplash, despite those who say otherwise for medicolegal reasons. $\mathrm{He}$ and his colleagues showed clearly that pain after cervical sprain injury was primarily correlated with the intensity of the initial pain, with the occurrence of premorbid injury and with age. Personality status before injury had no bearing on the outcome, and the intensity of pain at the beginning of injury was also correlated with depression or cognitive change later (1).

These important findings were not the subject of the present symposium. Rather, the meeting was used to put together a series of contributions that examined the present status of knowledge about the condition.
The symposium included more papers than are included here. All the plenary session lectures, including certain German ones dealing primarily with Swiss medicolegal issues, were published in 2002 by Stämpfli Publishers Ltd, Berne. For this occasion, we present all those plenary session papers that were published in English and some selected papers from the free contributions.

The present issue contains a foreword and seven papers, and a further six will follow in the next issue. I am confident that the material will be of interest and helpful to many readers of Pain Research \& $M$ anagement. It introduces the European work (and some continuing A ustralian and $\mathrm{N}$ orth A merican work) to $\mathrm{a} C$ anadian audience to an extent that has perhaps not previously been achieved.

\section{REFERENCES}

1. Radanov BP, Stefano GD, Schnidrig A, Ballinari P. Role of psychosocial stress in recovery from common whiplash. Lancet 1991;388:712-5.

The views expressed in this editorial are those of the authors and are not intended to reflect the opinions of the C anadian Pain Society or Pulsus Group Inc

C orrespondence: Dr H arold M erskey, 1001 A delaide Street N orth, Suite 205, London, 0 ntario N 5Y 2M 6. Telephone 519-434-8333, fax 519-434-8880, e-mail merskey@on.aibn.com 


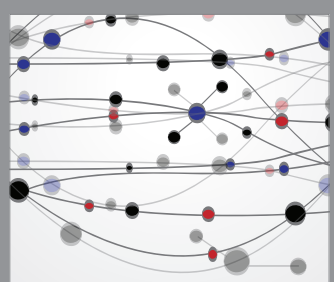

The Scientific World Journal
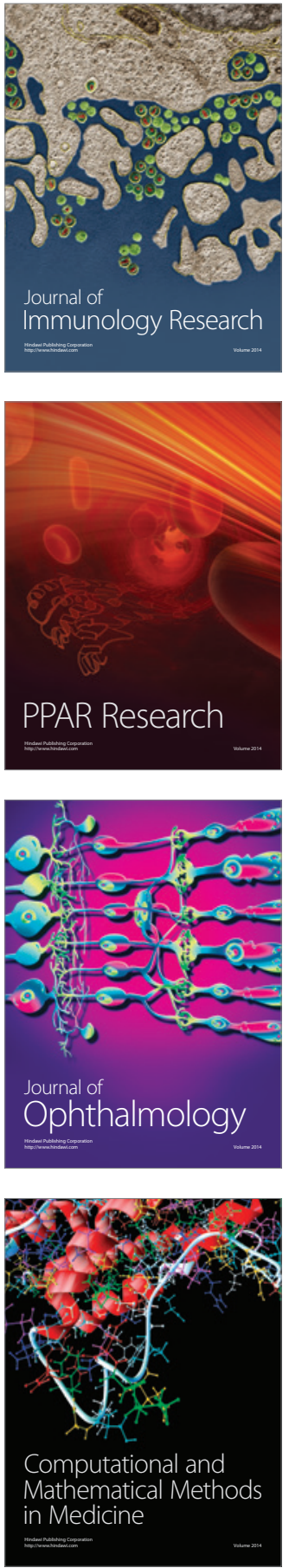

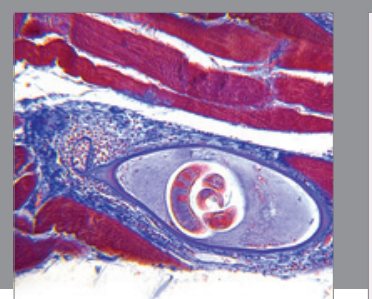

Gastroenterology Research and Practice

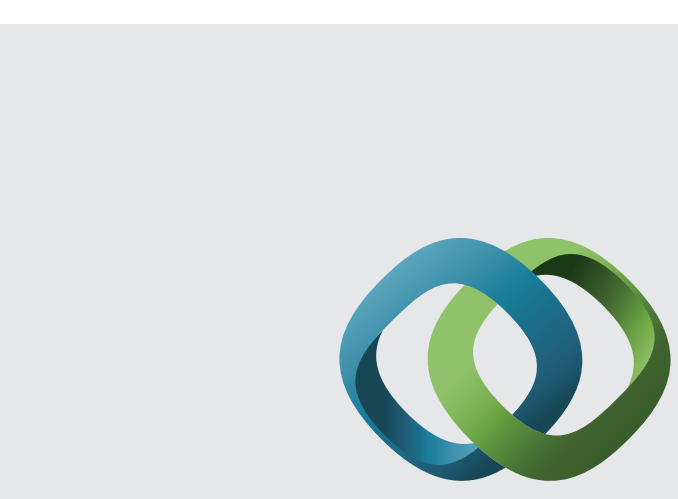

\section{Hindawi}

Submit your manuscripts at

http://www.hindawi.com
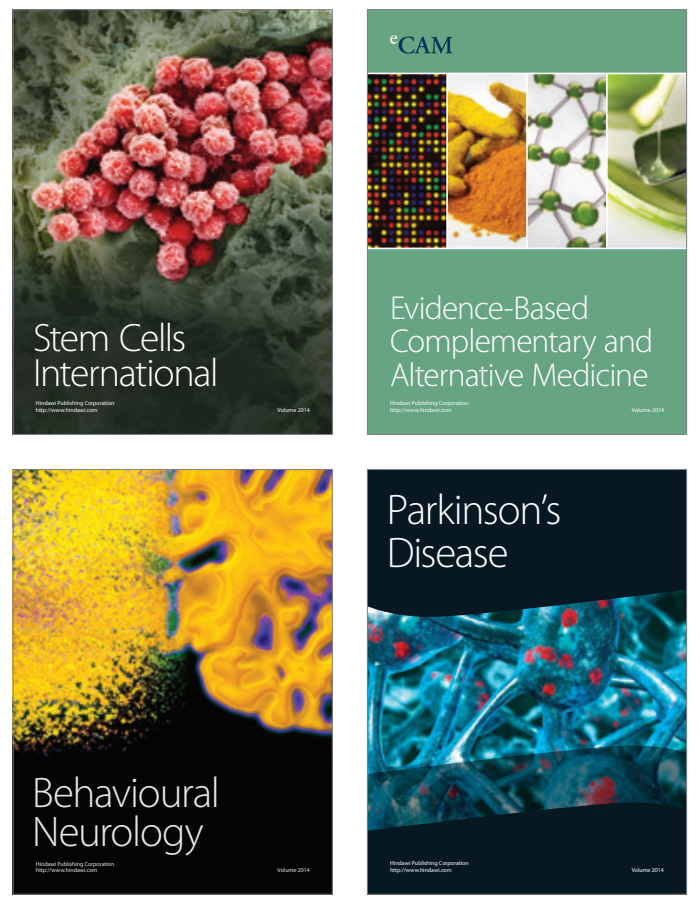
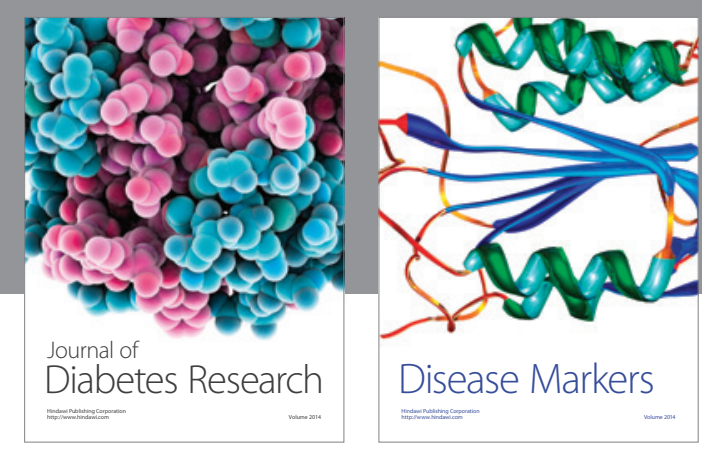

Disease Markers
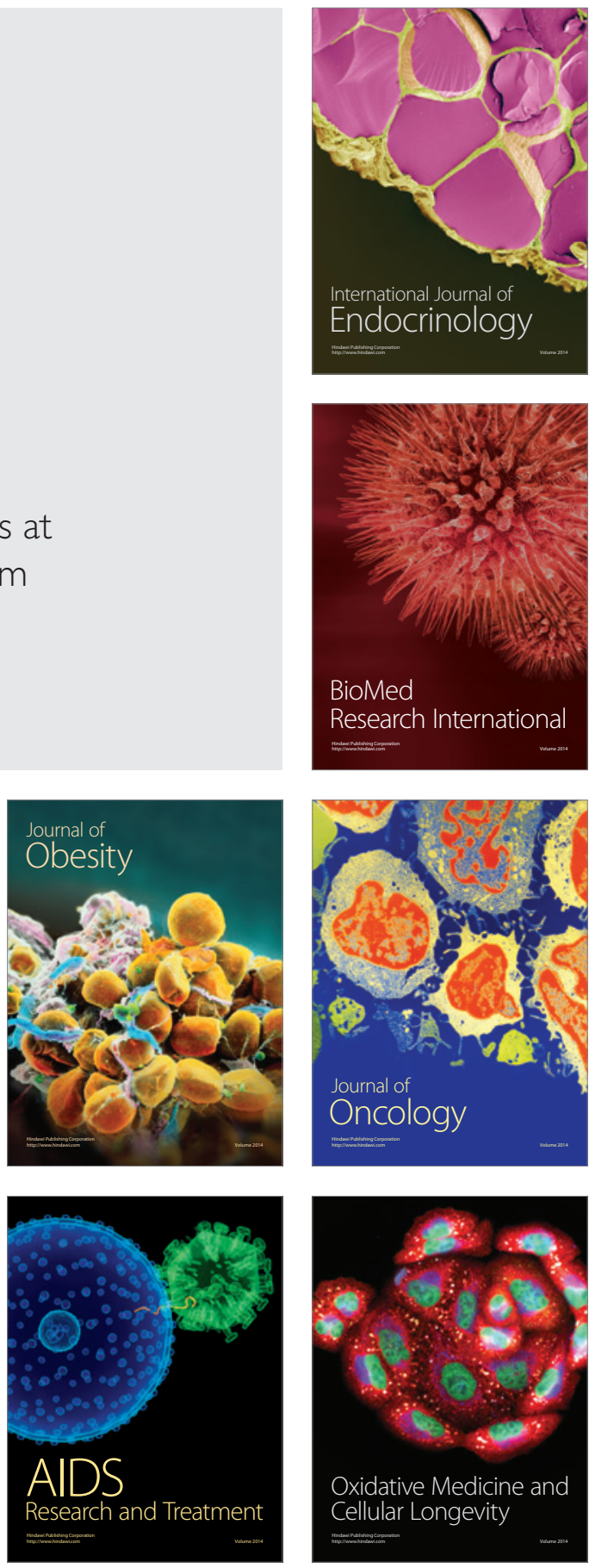